УДК 616.8-008.64:616.891.6:615.214:616.8-085.851:616-092.11-048-78

Для цитирования: Погосова И.А., Голозубова К.Н. Влияние комплексной терапии на качество жизни больных коморбидными депрессивным и паническим расстройствами. Сибирский вестник психиатрии и наркологии. 2019; 1 (102): 18-27. https://doi.org/10.26617/1810-3111-2019-1(102)-18-27

\title{
Влияние комплексной терапии на качество жизни больных коморбидными депрессивным и паническим расстройствами
}

\section{Погосова И.А. ${ }^{1}$, Голозубова К.Н. ${ }^{2}$}

\author{
${ }^{1}$ Курский государственный медицинский университет \\ Россия, 305041, Курск, ул. К. Маркса, 3 \\ ${ }^{2}$ Пристенская центральная районная больница Комитета здравоохранения Курской области \\ Россия, 306200, Курская область, п. Пристень, ул. Октябрьская, 28
}

\section{PEЗЮME}

Введение. Актуальность изучения проблемы коморбидных панических и депрессивных расстройств обусловлена высокой распространенностью указанных состояний в популяции. Материалы и методы. В статье обсуждаются результаты изучения динамики психологических особенностей, показателей качества жизни больных коморбидными депрессивным и паническим расстройствами в процессе сочетанного применения фармакологических и психотерапевтических методов лечения. Обследованы 50 пациентов с коморбидными депрессивным и паническим расстройствами. 25 пациентов основной группы получали сочетанную фармако- и психотерапию. В лечебном процессе 25 больных контрольной группы единственным способом коррекции клинико-психологических проявлений болезни являлась фармакотерапия. Представлены результаты изучения клинико-психологических и патопсихологических параметров у больных основной и контрольной групп до и после терапии с их последующим сравнительным анализом. Результаты. Применение комплексного подхода в лечебном процессе привело к стабилизации эмоциональных проявлений болезни, психологическому благополучию пациентов, повышению показателей качества их жизни. Заключение. Проведенное исследование позволяет сделать вывод о целесообразности включения предложенной психотерапевтической программы в лечебный процесс при коморбидных паническом и депрессивном расстройствах.

Ключевые слова: депрессивное расстройство, паническое расстройство, коморбидность, когнитивнобихевиоральная психотерапия, качество жизни, психологическое благополучие.

\section{ВВЕДЕНИЕ}

Научный интерес к проблеме коморбидных аффективных и тревожных расстройств обусловлен высокой распространённостью последних в популяции [15]. Как правило, коморбидные аффективные и тревожные расстройства впервые диагностируются в возрасте наибольшей социальной активности, имеют хроническое, склонное к частым обострениям течение. В работе с данной категорией пациентов возникают проблемы диагностического характера, сложности в подборе психофармакологических и психотерапевтических способов коррекции указанных состояний, что является основанием для развития психосоциальной дезадаптации у больных $[1,4,10,11,12,13]$. По данным зарубежных и отечественных исследователей, коморбидность рассматривается как одна из основных причин, оказывающих негативное влияние на течение основного заболевания, физиологическое и психологическое благополучие и качество жизни больных $[6,8,10,11,12$, 13, 14, 18, 19, 20].

В ряде исследований приводятся результаты изучения клинико-психопатологических и психологических особенностей, обсуждаются показатели социального функционирования у больных, обнаруживающих сочетанные формы аффективных и панических расстройств [2, $5,16]$. В работе В.В. Русая и др. были изучены показатели социального функционирования у больных паническими расстройствами, обнаружено снижение психического и физического составляющих здоровья, описаны затруднения социального функционирования [14]. По мнению Т.Е. Андрющенко и др., А.Ю. Голосовой, болезненные переживания пациентов, страдающих паническими и тревожными расстройствами, находят негативное отражение в их представлениях о себе и адаптационных возможностях, а также выстраивании ими собственной жизненной картины $[1,4]$. До настоящего времени остается актуальным вопрос использования сочетанных форм терапии в процессе лечебного сопровождения пациентов, обнаруживающих сочетанные формы депрессивных и панических расстройств [3, 7, 8, 9, 10 , $11,12,13,17,19]$. 
В связи с этим возникла необходимость изучения эффективности применения комплексного подхода в лечении больных коморбидными депрессивным и паническим расстройствами с целью гармонизации показателей эмоциональной сферы, достижения психологического благополучия пациентов и повышения качества их жизни.

\section{ЦЕЛЬ ИССЛЕДОВАНИЯ}

Изучение эффективности использования сочетанных психофармакологических и психотерапевтических мероприятий для стабилизации психического состояния, достижения психологического благополучия и повышения качества жизни больных коморбидными депрессивным и паническим расстройствами.

\section{МАТЕРИАЛЫ И МЕТОДЫ}

В период с 2015 по 2018 г. на базе психосоматического отделения ОБУЗ «Областная клиническая наркологическая больница» Комитета здравоохранения Курской области, дневного стационара № 2 с АРЦ ОБУЗ «Курская клиническая психиатрическая больница имени Святого Великомученика и Целителя Пантелеймона» обследовано 50 пациентов (100\%) с коморбидными депрессивным (депрессивный эпизод легкой и средней степени - F32.0, F32.10; рекуррентное депрессивное расстройство, текущий эпизод легкой и средней степени - F33.0; F33.1) и паническим (F41.0) расстройствами. Клиническую диагностику данных коморбидных заболеваний проводили на основании МКБ-10. Средняя продолжительность указанных расстройств составила $2 \pm 1,25$ года. Средний возраст обследованных больных $-33,9 \pm 4$ года. В лечебном процессе больных основной группы использовалась комбинация фармакотерапевтических и психотерапевтических методов (25 больных - 50,0\%). Больные контрольной группы получали только психофармакотерапию (25 больных - 50,0\%). Исследование носило двухэтапный характер. Так, на первом этапе исследования (до осуществления лечебных мероприятий) были изучены психологические характеристики и показатели качества жизни больных основной и контрольной групп. Второй этап (после проведенных лечебных мероприятий) был направлен на повторное измерение психологических особенностей и показателей качества жизни у больных основной и контрольной групп с целью их последующего сравнения. Степень симптоматического улучшения состояния больных определяли с использованием ряда психодиагностических методов. Шкалы: ситуативной и личностной тревожности Спилбергера-Ханина, самооценки депрессии Цунга, оценки тревоги Шихана, Гамильтона. Анализ степени осознания больными психологических механизмов болезни был основан на результатах изучения методики «Диагностика самочувствия, активности и настроения», «Личностностном опроснике Бехтеревского института» (ЛОБИ). Степень социального функционирования больных проанализирована посредством «Анкеты качества жизни MOS-SF-36, «Методики оценки качества жизни больных и инвалидов NAIF», «Шкалы психологического благополучия К. Риффа». Для оценки статистической достоверности полученных результатов применялся непараметрический Uкритерий Манна-Уитни с помощью статистического пакета StatSoft STATISTICA 6.0.

В лечебную программу больных основной и контрольной групп были включены антидепрессанты, «мягкие» нейролептики, транквилизаторы.

Для эффективного лечения больных основной группы, наряду с психофармакологической коррекцией, была проведена психотерапевтическая программа, состоящая из методов когнитивно-бихевиоральной психотерапии, релаксационных техник для снятия напряжения, эмоционально-позитивного разъяснения, рациональной психотерапии. С пациентами основной и контрольной групп проводились индивидуальные и групповые занятия. Мишенями для индивидуальной психотерапии у больных выступили эмоциональное напряжение, внутриличностный конфликт, установка на будущее, отношение к болезни, личностные границы и собственная идентичность.

Целью психотерапии было изменение представлений пациента о физиологических механизмах становления панических атак; трансформация дезадаптивных форм поведения в адаптивные; снижение психоэмоционального напряжения; формирование позитивных и негативных личностных качеств, положительных ресурсов для подкрепления, поведения, направленного на борьбу со сложившейся ситуацией; развитие установок на положительный результат лечения и выздоровление, а также разрешение сложных жизненных ситуаций; трансформация познавательной структуры личностного «Я», своих когнитивных установок для становления дальнейшего конструктивного поведения в отношении жизненной ситуации и своего заболевания; проведение ра- 
боты, направленной на осознание пациентом своих возможностей, вариантов построения картины будущего, своих установок, осознание шагов, необходимых для реализации поставленных целей; укрепление личностных границ, собственной идентичности для осознания пациентами своего внутреннего пространства и способности выбирать способ эмоционального ответа на внешние и внутренние события, а также контроль своего эмоционального фона.

Для решения психотерапевтических задач применены ряд методов и техник различных психотерапевтических направлений: «метод пустого стула», техника «кто Я?», «создание желаемого будущего», «метод колонок», «формулировка результата». Продолжительность занятий составила 4 недели, по 30-40 минут в день. Терапевтические группы формировались с учетом нозологического принципа, продолжительности и степени тяжести клиникопсихологических проявлений заболевания. Психотерапевтическое воздействие состояло из трех психотерапевтических этапов. В ходе первого психотерапевтического этапа, направленного на психообразование, больным раскрывали суть приступа панической атаки, объясняли, что панические атаки являются естественным биологическим процессом, возникающим в ответ на негативные мысли и чувства, а физиологические изменения в период приступа способствуют формированию мышечного напряжения у последних. С помощью указанного психотерапевтического этапа проводилось снижение эмоционального напряжения у пациентов. Содержанием второго психотерапевтического этапа являлась работа со страхом и негативным эмоциональным фоном больных. Для реализации данного этапа нами использовались когнитивно-бихевиоральные методы (метод пяти колонок, систематическая десенсибилизация), релаксационные техники (релаксация по Джекобсону, АТ1, АТ2), рациональная психотерапия и эмоционально-позитивное разъяснение, в рамках которых проводилась работа с личностными установками и формировалась мотивация у пациентов на лечение и выздоровление («информирование», «анализ будущего», «создание коллажа», техника «создание желаемого будущего»). В рамках когнитивного направления использовался метод пяти колонок, с помощью которого больного обучали контролировать свои эмоциональные реакции, возникающие во время панической атаки. Таким образом, у пациентов основной группы развивалось ощущение безопасности и защищенности. Третий этап психотерапии заключался в проведении индивидуальной работы, направленной на личные переживания пациентов, внутриличностные конфликты, самопринятие, самооценку больных, изменение своей позиции в рамках сложившейся ситуации.

\section{ОБСУЖДЕНИЕ РЕЗУЛЬТАТОВ}

Данные, полученные в ходе проведенного исследования психоэмоционального состояния 50 больных, до начала лечебных мероприятий статистически значимо не отличались. У $100 \%$ пациентов обнаружены низкие значения показателей методики САН («самочувствие» $32,14 \pm 8,52$, «активность» - 33,78 $\pm 8,97$, «настроение» - 34,32 $\pm 7,1)$. Уровень тревоги по шкале Шихана достиг клинически выраженных значений и составил 45,06士19,96. По шкале Гамильтона была зафиксирована тяжелая степень выраженности тревоги $(25,02 \pm 5,13)$. По шкале Цунга выявлено, что уровень депрессии достигал уме-

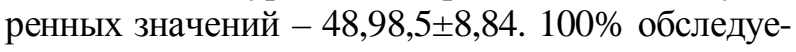
мых больных имели высокие значения по показателям личностной и ситуативной тревожности $(49,6 \pm 6,32$ и 51,52 $\pm 5,09$ соответственно). Качество жизни (анкета качества жизни MOS-SF-36) пациентов основной и контрольной групп соответствовало умеренному уровню - 41,06 $\pm 15,9$. Согласно результатам анализа анкеты NAIF у обследованных больных выявлено умеренное снижение интегрального показателя качества жизни $(41,64 \pm 13,29)$. Среди типов отношения к болезни у 50 обследованных пациентов обнаружены следующие: тревожный (52,0\%), ипохондрический $(28,0 \%)$, сенситивный $(12,0 \%)$, меланхолический $(8,0 \%)$. По ряду шкал, отражающих психологическое благополучие пациентов (шкала Рифф), выявлено снижение показателей: «позитивные отношения с другими» $(53,1 \pm 7,08)$, «автономия» $(52,16 \pm 7,99)$, «управление средой» $(53,92 \pm 7,95)$, «самопринятие» $(53,54 \pm 11,6)$, «баланс аффекта» $(69,48 \pm 11,08)$, «осмысленность жизни» $(47,26 \pm 7,61)$, «человек как открытая система» $(55,8 \pm 7,96)$. В пределах средних значений находится показатель общего психологического благополучия.

Следует отметить, что изменения в психическом и физическом состоянии обследованных больных приводят к снижению их адаптационных возможностей, затрудняют у них процесс построения картины настоящего и будущего, оказывают негативное влияние на уровень межличностного взаимодействия и социальный статус в обществе. 
Сравнительная оценка средних значений эмоциональной сферы, психологического благополучия и качества жизни пациентов основной и контрольной групп (ОГ и КГ) после проведенных им лечебных мероприятий представлены на рисунках 1-4.

На рисунке 1 показано частотное распределение средних показателей эмоциональной сферы больных ОГ и КГ после лечебных мероприя- тий. Проведенный статистический анализ выявил различия, достигающие высокого уровня статистической значимости $(\mathrm{p} \leq 0,01)$ у больных основной группы по ряду шкал: «тревога» (шкала Шихана) $(\mathrm{p}=0,000238)$, «тревога» (Гамильтон) ( $\mathrm{p}=0,000262), \quad$ «депрессия» (шкала Цунга) ( $\mathrm{p}=0,000013)$, «ситуативная тревожность» (шкала Спилбергера-Ханина) ( $\mathrm{p}=0,015536)$, «настроение» $(\mathrm{CAH})(\mathrm{p}=0,001837)$.

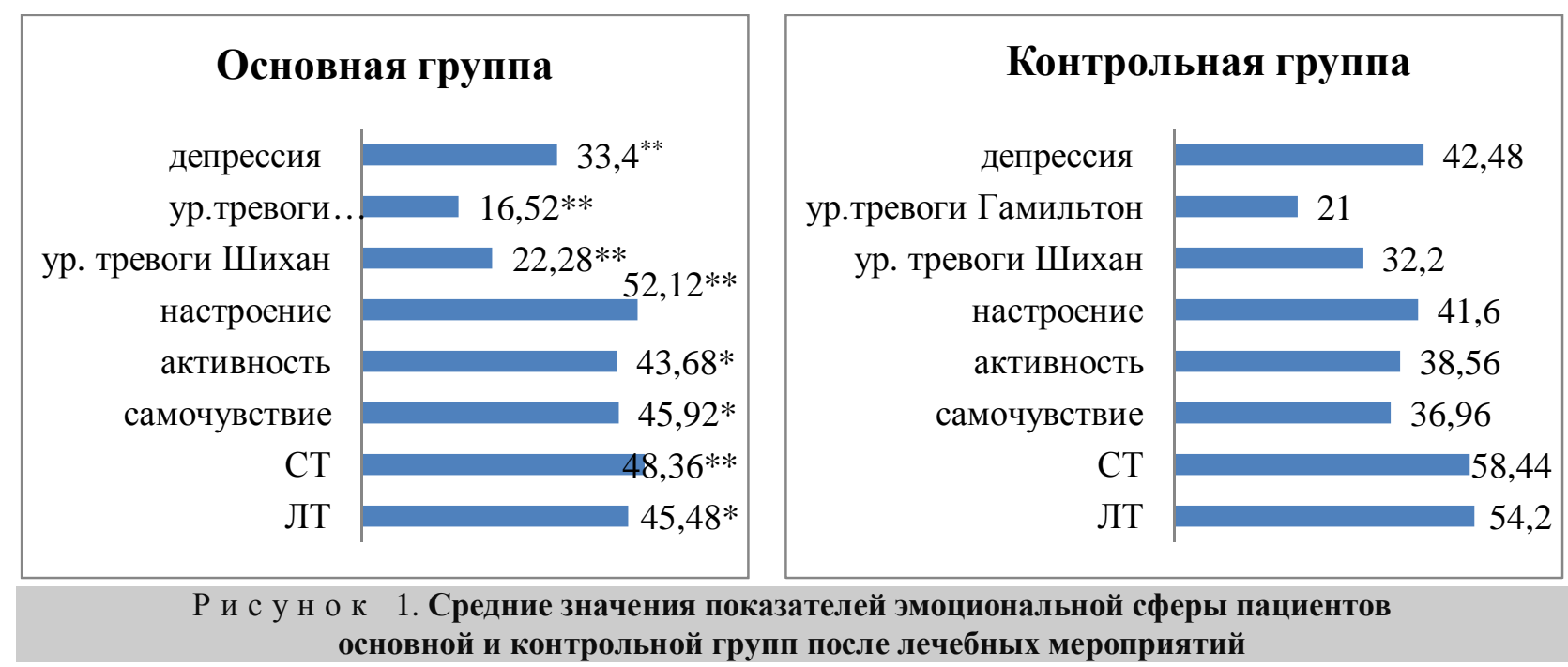

П р и м е ч а н и е. СТ - ситуативная тревожность. ЛТ - личностная тревожность. *- Различия на достоверном уровне статистической значимости $(0,01<\mathrm{p} \leq 0,05)$; **- различия на высоком уровне статистической значимости $(\mathrm{p} \leq 0,01)$.

Позитивное влияние психотерапии на психоэмоциональный фон больных основной группы подтверждается обнаруженными на достоверном уровне статистической значимости $(0,01<\mathrm{p} \leq 0,05)$ результатами по шкалам: «самочувствие» $(\mathrm{p}=0,021106)$, «активность» $(\mathrm{p}=0,040879)(\mathrm{CAH})$, «личностная тревожность» $(\mathrm{p}=0,037456)$ (Спилбергера-Ханина). Как видно из рисунка 1, использование в лечебном процессе пациентов основной группы фармакои психотерапевтических мероприятий привело к снижению показателей по ряду шкал: «тревога» (шкала Шихана) - на 9,92 балла, «тревога» (шкала Гамильтона) - на 4,48 балла, «депрессия» (Цунга) - на 9,08 балла, «ситуативная» (на 10,08 балла) и «личностная» (на 8,72 балла) тревожность (шкала Спилбергера-Ханина).

У больных основной группы произошло повышение значений по трем шкалам методики САН. Так, показатели шкалы «настроение» улучшились на 10,5 балла, «самочувствие»- на 8,96 балла, «активность» - на 5,12 балла. Следует отметить, что проведенные лечебные мероприятия оказали позитивное влияние на психологический статус больных основной груп- пы. Зафиксирована значительная стабилизация общего самочувствия, настроения и активности, существенно снизился уровень ситуативной и личностной тревожности. У $100 \%$ больных основной группы сочетанное использование психо- и фармакотерапии привело к стабилизации их психоэмоционального состояния.

Из рисунка 2 следует, что использование в лечебном процессе больных основной группы психотерапии привело к росту удельного веса пациентов с гармоничным типом отношения к болезни до 40,0\%, снижению числа лиц с тревожным типом на $20,0 \%$ и полному исчезновение пациентов с меланхолическим типом. Психотерапевтическая программа обеспечила возможность больным основной группы изменить прежнюю позицию в отношении принятия своего заболевания. После психотерапии пациенты основной группы стали более реалистично смотреть на сложившуюся жизненную ситуацию, научились переключать свое внимание с проявлений заболевания на круг повседневных дел, без особых сложностей вовлекались в межличностное общение, что позволило расширить круг их интересов. 

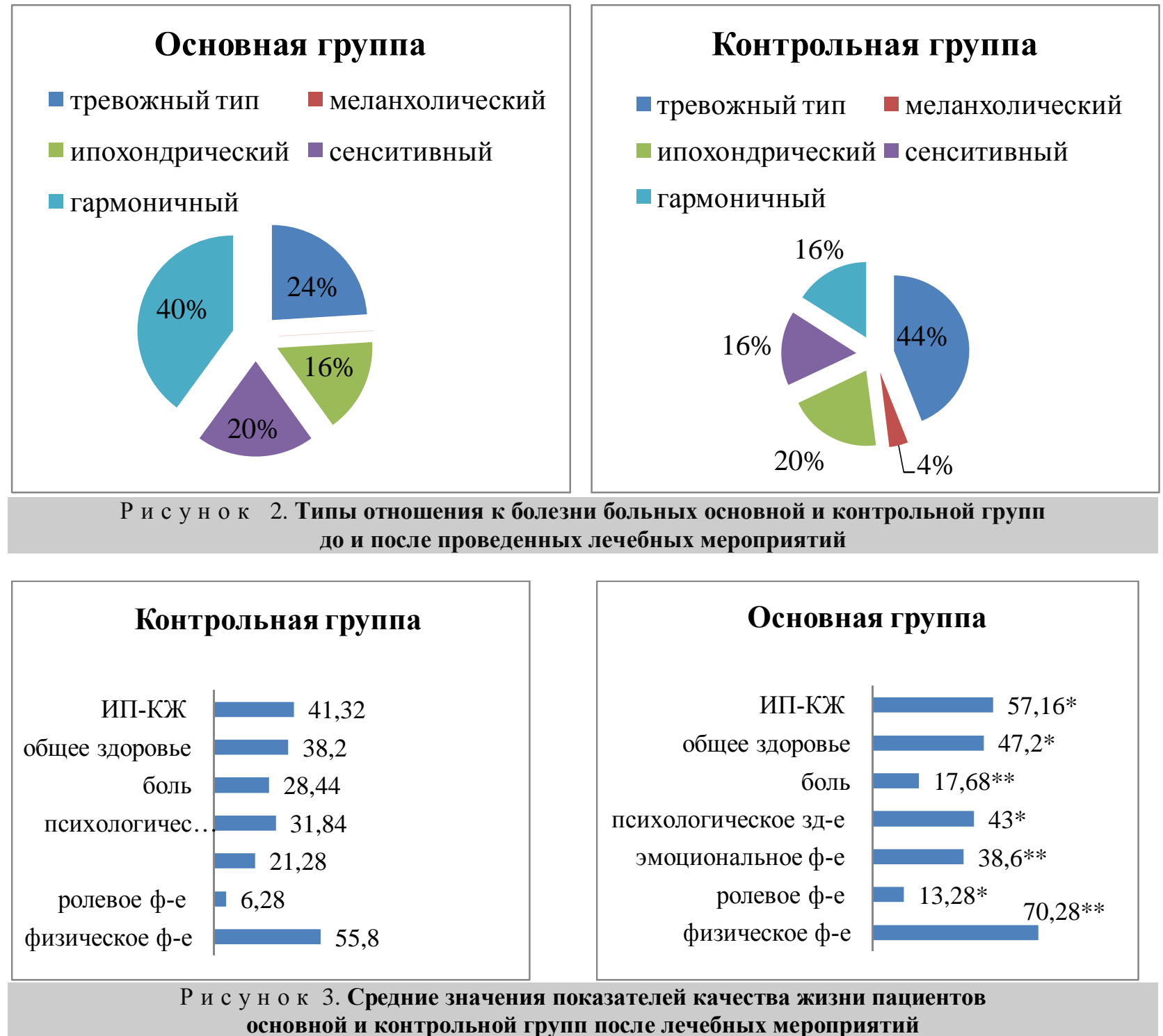

Примечание. ИП-КЖ - интегральный показатель качества жизни. * - Различия на достоверном уровне статистической значимости $(0,01<\mathrm{p} \leq 0,05)$; ** - различия на высоком уровне статистической значимости $(\mathrm{p} \leq 0,01)$.

На рисунке 3 отражены результаты распределения средних значений по шкалам, имеющим различия на высоком $(\mathrm{p} \leq 0,01)$ уровне статистической значимости по показателям качества жизни больных: «физическое функционирование» $(\mathrm{p}=0,001613)$, «эмоциональное функционирование» $(\mathrm{p}=0,015100)$, «боль» $(\mathrm{p}=0,006236)$. На достоверном $(0,01<\mathrm{p} \leq 0,05)$ уровне статистической значимости выявлены различия по шкалам: «ролевое функционирование» ( $=0,059389)$, «психологическое и общее здоровье» ( $\mathrm{p}=0,035308 ; \mathrm{p}=0,015100)$, «интегративный показатель КЖ» $(\mathrm{p}=0,035269)$. У больных основной группы проведенная фармако- и психотерапия привела к повышению показателей качества жизни по ряду шкал анкеты MOS-SF-36: «физическое функционирование» (на 14,48 балла), «эмоциональное функционирование» (на 17,32 балла), «общее здоровье» (на 9 баллов), «ролевое функционирование» (на 7 баллов), «психологическое здоровье» (на 11 баллов) и снижению показателя «интенсивность боли» (на 10,76 балла). Интегральный показатель качества жизни больных анкеты NAIF был повышен (на 15,84 балла). Таким образом, включение предложенной психотерапевтической программы в лечебный процесс при коморбидных депрессивном и паническом расстройствах способствовало нормализации эмоционального фона пациентов, улучшению качества жизни.

Анализ изменений показателей психологического благополучия (шкала Рифф) у пациентов основной и контрольной групп в результате проведенных лечебных мероприятий выявил ряд отличий (рис. 4). 


\section{Основная группа}

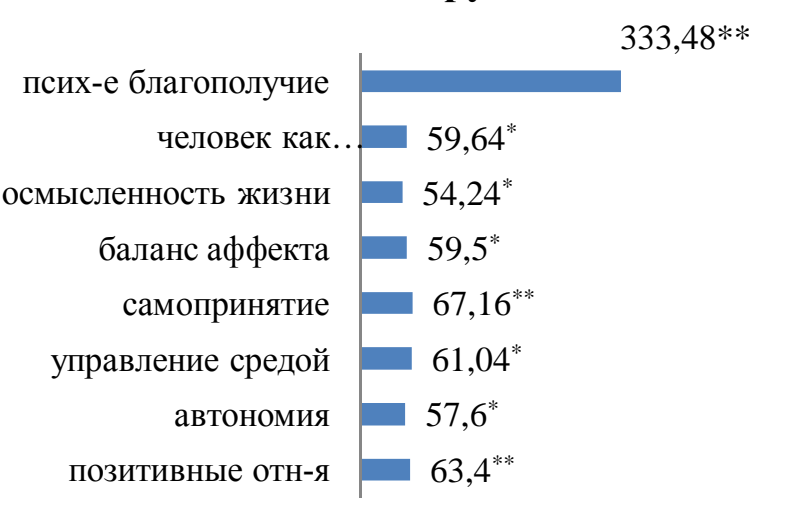

\section{Контрольная группа}

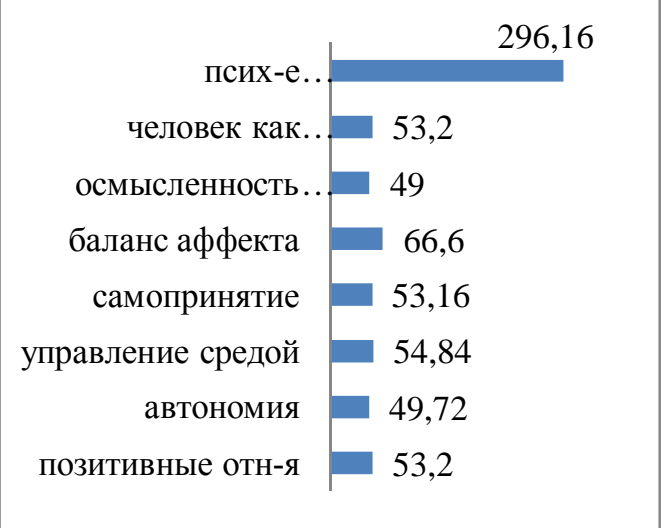

Рисунок 4. Средние значения показателей психологического благополучия пациентов основной и контрольной групп после лечебных мероприятий

П р и м е ч а н и е. *- Различия на достоверном уровне статистической значимости $(0,01<\mathrm{p} \leq 0,05)$; **различия на высоком уровне статистической значимости $(\mathrm{p} \leq 0,01)$.

Так, на достоверном уровне статистической значимости $(0,01<\mathrm{p} \leq 0,05)$ обнаружены изменения по следующим шкалам: «автономия» $(\mathrm{p}=0,022345), \quad$ «баланс аффекта» (p=0,033467), «осмысленность жизни» ( $=0,023406)$, «человек как открытая система» $(\mathrm{p}=0,024508)$. На высоком уровне статистической значимости $(\mathrm{p} \leq 0,1)$ диагностированы различия по ряду шкал: «позитивные отношения с другими» $(\mathrm{p}=0,001377)$, «самопринятие» ( $=0,0014583)$, «психологическое благополучие» $(\mathrm{p}=0,0013568)$. В основной группе больных в процессе психо- и фармакотерапии отмечена положительная динамика средних значений по следующим показателям психологического благополучия: «позитивные отношения» - на 10,2 балла, «автономия» - на 7,8 балла, «управление средой»- на 6,2 балла, «личностный рост» - на 5,9 балла, «самопринятие» - на 14 баллов, «осмысленность жизни» - на 5,24 балла, «человек как открытая система»на 6,49 балла. Показатели «баланса аффекта» были снижены на 7,1 балла, в то же время зарегистрировано увеличение показателя «общее психологическое благополучие» на 37,32 балла.

\section{ОБСУЖДЕНИЕ РЕЗУЛЬТАТОВ}

Реализация комплексного фармако- и психотерапевтического воздействия для больных коморбидными депрессивным и паническим расстройствами оказало благоприятное влияние не только на физическое состояние, но и на психологические параметры пациентов: способствовало стабилизации их эмоционального фона и становлению психологического благополучия, что в целом повысило качество жизни пациентов. Сочетанные фармако- и психотерапевтические мероприятия в рамках коморбид- ных депрессивного и панического расстройств привели к изменениям в социальной активности больных за счет расширения их межличностных контактов, формированию у больных умений выстраивать адекватные цели и образ будущего с возможностью реализации себя в нем. У больных сформировались самостоятельность, независимость в принятии решений и позитивное отношение к себе.. Пациенты изменили прежнее отношение к заболеванию за счет уменьшения степени фиксации внимания на собственных переживаниях, с интересом погрузились в повседневные дела и семейные заботы. Проведенная индивидуальная психотерапевтическая работа с пациентами, обнаруживающими коморбидные депрессивное и паническое расстройства, способствовала повышению уровня их самооценки, формированию осознания ими своей роли в социальном окружении, разрешению существующих внутриличностных конфликтов, принятию себя и развитию умений и навыков самостоятельно находить выход из сложных жизненных ситуаций.

\section{ЗАКЛЮЧЕНИЕ}

Полученные результаты исследования дают возможность констатировать необходимость использования сочетанных фармакологических и психотерапевтических методов в лечебном процессе больных коморбидными депрессивным и паническим расстройствами. Реализация комплексного подхода в лечебном процессе больных коморбидными депрессивным и паническим расстройствами приведет к гармонизации эмоционального фона пациентов, психологическому благополучию и повысит качество их жизни. 


\section{КОНФЛИКТ ИНТЕРЕСОВ}

Авторы заявляют об отсутствии возможных конфликтов интересов в связи с публикацией данной статьи.

\section{ИСТОЧНИК ФИНАНСИРОВАНИЯ}

Авторы заявляют об отсутствии финансирования при проведении исследования.

\section{СООТВЕТСТВИЕ ПРИНЦИПАМ ЭТИКИ}

Исследование проведено с соблюдением норм современной биомедицинской этики и этических стандартов, разработанных в соответствии с Хельсинской декларацией ВМА (протокол заседания Комитета по этике Курского государственного медицинского университета № 5 от 14.05.2015).

\section{ЛИТЕРАТУРА}

1. Андрющенко Т.Е., Живаева Ю.В. Представление о будущем у лиц с паническими и тревожно-фобическими расстройствами. Психологическое здоровье человека: жизненный ресурс и жизненный потенциал: материалы II Междунар. науч.-практ. конф. (г. Красноярск, 27-28 ноября 2015 г.) / гл. ред. И.О. Логинова. Красноярск: КрасГМУ, 2015: 182-188.

2. Арутюнова Э.Э., Цыганков Б.Д. Аффективные расстройства в структуре панических атак. $\mathrm{Cu}$ бирский вестник психиатрии и наркологии. Материалы научно-практической конференции с международным участием «Психическое здоровье населения Сибири и Дальнего Востока. 2006; Приложение (41): 28-9.

3. Воробьёва О.В. Диагностика и терапия панических расстройств. Терапия панических расстройств. 2010; 1: 30-35.

4. Голосова А.Ю. Самовосприятие и образ будущего у пациентов с паническими атаками. Личность в экстремальных условиях и кризисных ситуациях жизнедеятельности: материалы 2-й Межрегиональной научно-практической конференции с международным участием (г. Владивосток, 8-17 июля 2013 г.) / под ред. Р.В. Кадырова. Владивосток: Тихоокеанский государственный университет, 2013: 158-162.

5. Горбунова А.А., Колюцкая Е.В. Паническое расстройство и аффективная патология (аспекты коморбидности). Журнал неврологии и психиатрии им. С.С. Корсакова. 2014; 114 (10): 10-12.

6. Кот Т.Н., Сирусина А.В., Шаламова Е.Ю. Латентные факторы качества жизни у больных с депрессивными расстройствами. Мир культуры, науки и образования. 2014; 1 (44): 342.

7. Кудинова Е.И. Особенности психотерапевтической коррекции эмоциональных нарушений у больных с паническими расстройствами. Медицинская психология. 2015; 3: 76-78.

8. Левин О.С., Ляшенко Е.А. Тревога и коморбидные состояния. Нервные болезни. 2016; 1: 28-34.
9. Немых Л.С., Куташов В.А. Терапия панического расстройства. Прикладные информачионные аспекты медииины. 2015; 18 (6): 63-67.

10. Погосова И.А. Клинические особенности панических расстройств при их сочетании с коморбидной психической и наркологической патологией. Неврологический вестник им. В.М. Бехтерева. 2012; 44 (3): 42-47.

11. Погосова И.А. Психологические особенности больных коморбидными генерализованным тревожным и депрессивным расстройствами. Курский научно-практический вестник «Человек и его здоровье». 2012; 4: 74-79.

12. Погосова И.А., Голозубова К.Н. Динамика психологических проявлений коморбидных панических и аффективных расстройств в процессе фармакологических и психотерапевтических мероприятий. Практическая медииина. 2017; 2, 1 (102): 40-44.

13. Погосова И.А., Погосов А.В., Федоренко Т.Ю. Оценка эффективности когнитивноповеденческой психотерапии у больных с коморбидными тревожными и аффективными расстройствами. Науково-практичний журнал Архів психіатріi. 2008; 14, 1 (52): 54-59.

14. Русая В.В., Воробьева О.В. Качество жизни больных паническим расстройством и факторы, его определяющие. Фарматека. 2011; 19: 96100.

15. Садыкова А.А. Клинические особенности депрессивных расстройств, сочетающиеся с тревожно-фобическими расстройствами. XVI съезд психиатров России. Всероссийская научнопрактическая конференция с международным участием. Психиатрия на этапах реформ: проблемы и перспективы (Казань, 23-26 сентября 2015 г.) [электронный ресурс]: тезисы под общей редакцией Н.Г. Незнанова. СПб.: Альта Астра, 2015: 71.

16. Семке В.Я., Погосова И.А. Психотерапия коморбидных тревожно-фобических и аффективных расстройств. Сибирский вестник психиатрии и наркологии. 2010; 5 (62): 50-57.

17. Тукаев Р.Д., Кузнецов В.Е. Когнитивноориентированная психотерапия при тревожных расстройствах: оценка в контролируемом исследовании. Социальная и клиническая психиатрия. 2015; 15 (2): 55-64.

18. Allen L.B., White K.S., Barlow D.H., Shear M.K., Gorman J.M., Woods S.W. Cognitive-Behavior Therapy (CBT) for panic disorder: relationship of anxiety and depression comorbidity with treatment outcome. J Psychopathol Behav Assess. 2010; 32 (2): 185-192. doi 10.1007/s10862-009-9151-3

19. Boswell J.F., Gallagher M.W., Sauer-Zavala S.E. et al. Patient characteristics and variability in adherence and competence in cognitive-behavioral therapy for panic disorder. Journal of Consulting and Clinical Psychology. 2013; 81 (3): 443-454 doi:10.1037/a0031437 
20. Brown G.W., Goldberg D., Kendler K.S., Sirovatka P.J. et al. (eds.) Psychosocial origins of depressive and anxiety disorders. Diagnostic issues in depression and generalized anxiety disorder. Arlington, Virginia, 2010: 303-332.

Погосова Инна Альбертовна, кандидат медицинских наук, доцент кафедры психиатрии и психосоматики. Голозубова Кристина Николаевна, медицинский психолог.

Погосова Инна Альбертовна, inchikp@yandex.ru

УДК 616.8-008.64:616.891.6:615.214:616.8-085.851:616-092.11-048-78

For citation: Pogosova I.A., Golozubova K.N. The influence of complex therapy on the quality of life of patients with comorbid depressive and panic disorders. Siberian Herald of Psychiatry and Addiction Psychiatry. 2019; 1 (102): 1827. https://doi.org/10.26617/1810-3111-2019-1(102)-18-27

\section{The influence of complex therapy on the quality of life of patients with comorbid depressive and panic disorders \\ Pogosova I.A. ${ }^{1}$, Golozubova K.N. ${ }^{2}$ \\ ${ }^{1}$ Kursk State Medical University \\ K. Marx Street 3, 305041, Kursk, Russian Federation \\ ${ }^{2}$ Pristenskaya Central District Hospital of the Health Committee of the Kursk Region \\ Oktyabrskaya Street 28, 306200, s. Pristen', Kursk Region, Russian Federation}

\section{ABSTRACT}

The relevance of the study of the problem of comorbid panic and depressive disorders is caused by high prevalence of the specified states in the population. Materials and Methods. This article is dedicated to the consideration of the dynamics of psychological characteristics, indicators of quality of life of patients with comorbid panic and depressive disorders in the process of combined use of pharmacological and psychotherapeutic methods. The paper presents the data of the study of 22 patients with comorbid panic and depressive disorders. The main group includes 11 patients who have received combined pharmacological and psychotherapeutic treatment. 11 patients of the control group have undergone pharmacotherapy. Clinical- psychological and pathopsychological parameters have been studied in patients of the main and control groups before and after therapy with their subsequent comparative analysis. Results. The use of an integrated approach in the treatment process has contributed to the normalization of the emotional background, has improved the psychological well-being of patients, and has improved their quality of life. Conclusion. The carried-out study allows drawing the conclusion on appropriateness of inclusion of the proposed psychotherapeutic program into medical process in comorbid panic and depressive disorders.

Keywords: panic disorder, depressive disorder, comorbidity, cognitive-behavioral psychotherapy, quality of life, psychological well-being.

\section{REFERENCES}

1. Andryushchenko I.E., Zhivaeva Yu.V. Predstavlenie o budushchem u lic s panicheskimi i trevozhno-fobicheskimi rasstrojstvami. Psihologicheskoe zdorov'e cheloveka: zhiznennyj resurs i zhiznennyj potencial [View of the future in individuals with panic and anxiety-phobic disorders. Psychological human health: life resource and potential]: proceedings of the II Intern. Scientific.-Pract. Conf. (Krasnoyarsk, November 27-28, 2015)]. I.O. Loginov, ed. Krasnoyarsk: Krasnoyarsk State Medical University, 2015: 182-188 (in Russian).

2. Arutyunova E.E., Tsygankov B.D. Affektivnye rasstrojstva $\mathrm{v}$ strukture panicheskih atak [Affective disorders in structure of the panic attacks]. Materials of scientific and practical conference with the international participation "Mental health of the population of Siberia and the Far East". Sibirskij vestnik psihiatrii $i$ narkologii - Siberian Herald of Psychiatry and Addiction Psychiatry. 2006; Suppl. (41): 28-9 (in Russian).

3. Vorobyeva O.V. Diagnostika i terapiya panicheskih rasstrojstv [Diagnostics and therapy of panic disorder]. Terapiya panicheskih rasstrojstv - Therapy of Panic Disorders. 2010; 1: 30-35 (in Russian)

4. Golosova A.Y. Samovospriyatie i obraz budushchego u pacientov s panicheskimi atakami. Lichnost' v ehkstremal'nyh usloviyah i krizisnyh situaciyah zhiznedeyatel'nosti [Self-perception and image of the future in patients with panic attacks. Personality in extreme conditions and crisis situations of life: proceedings of the 2 nd interregional scientific-practical conference with international participation] (Vladivostok, from 8 to 17 July 2013)]. 
R.V. Kadyrov, ed. Vladivostok: Pacific National University, 2013: 158-162 (in Russian).

5. Gorbunova A.A., Kolyutskaya E.V. Panicheskoe rasstrojstvo i affektivnaya patologiya (aspekty komorbidnosti) [Panic disorder and affective pathology (aspects of comorbidity)]. Zhurnal nevrologii $i$ psihiatrii im. S.S. Korsakova - S.S. Korsakov Journal of Neurology and Psychiatry. 2014; 114 (10): 10-12 (in Russian).

6. Kot T.N., Sirotina A.V., Shalamova E.Yu. Latentnye faktory kachestva zhizni u bol'nyh s depressivnymi rasstrojstvami [Latent factors of the quality of life in patients with depressive disorders]. Mir kul'tury, nauki i obrazovaniya - World of Culture, Science and Education. 2014; 1 (44): 342 (in Russian).

7. Kudinova E.I. Osobennosti psihoterapevticheskoj korrekcii ehmocional'nyh narushenij u bol'nyh s panicheskimi rasstrojstvami [Psychotherapeutic correction of emotional disorders in panic disorder patients]. Medicinskaya psihologiya - Medical Psychology. 2015; 3: 76-78 (in Russian).

8. Levin O.S., Lyashenko E.A. Trevoga i komorbidnye sostoyaniya [Anxiety and comorbid conditions]. Nervnye bolezni - Nervous Diseases. 2016; 1: 28-34 (in Russian)

9. Nemykh L.S., Kutasov V.A. Terapiya panicheskogo rasstrojstva [Therapy of panic disorder]. Prikladnye informacionnye aspekty mediciny - Applied Information Aspects of Medicine. 2015; 18 (6): 63-67 (in Russian).

10. Pogosova I.A. Klinicheskie osobennosti panicheskih rasstrojstv pri ih sochetanii s komorbidnoj psihicheskoj i narkologicheskoj patologiej [Clinical features of panic frustration at their combination to comorbid mental and narcological pathology]. Nevrologicheskij vestnik im. V.M. Bekhtereva Neurologic messenger. The magazine of V.M. Bekhterev. 2012; 44 (3): 42-47 (in Russian).

11. Pogosova I.A. Psihologicheskie osobennosti bol'nyh komorbidnymi generalizovannym trevozhnym i depressivnym rasstrojstvami [Psychological features of patients with comorbid generalized anxiety and depressive disorders]. Kurskij nauchnoprakticheskij vestnik "Chelovek $i$ ego zdorov'e»Kursk scientific and practical bulletin "Individual and Health”. 2012; 4: 74-79 (in Russian)

12. Pogosova I.A., Golozubova K.N. Dinamika psihologicheskih proyavlenij komorbidnyh panicheskih i affektivnyh rasstrojstv $\mathrm{v}$ processe farmakologicheskih i psihoterapevticheskih meropriyatij [Dynamics of psychological manifestations of panic and affective disorders in the process of pharmacological and psychotherapeutic measures] Prakticheskaya medicina - Practical Medicine. 2017; 2, 1 (102): 40-44 (in Russian).

13. Pogosova I.A., Pogosov A.V., Fedorenko T.Y. Ocenka ehffektivnosti kognitivno-povedencheskoj psihoterapii u bol'nyh s komorbidnymi trevozhnymi i affektivnymi rasstrojstvami [Assessment of the ef- fectiveness of cognitive-behavioral psychotherapy for patients with comorbid anxiety and affective disorders]. Arhiv psihiatrii - Archive of Psychiatry. 2008; 14, 1 (52): 54-59 (in Russian).

14. Rusaya V.V., Vorobyeva O.V. Kachestvo zhizni bol'nyh panicheskim rasstrojstvom i faktory, ego opredelyayushchie. [Quality of life of patients with panic disorder and its determinants]. Farmateka Pharmateca. 2011; 19: 96-100 (in Russian).

15. Sadykova A.A. Klinicheskie osobennosti depressivnyh rasstrojstv, sochetayushchiesya s trevozhnofobicheskimi rasstrojstvami. XVI s"ezd psihiatrov Rossii. Vserossijskaya nauchno-prakticheskaya konferenciya s mezhdunarodnym uchastiem. Psihiatriya na ehtapah reform: problemy i perspektivy (Kazan', 23-26 sentyabrya 2015 g.) [ehlektronnyj resurs]: tezisy pod obshchej redakciej N.G. Neznanova [The clinical features of depressive disorders which are combined with anxiety-phobic disorders. The XVI Congress of Psychiatrists of Russia]. The All-Russian scientific and practical conference with the international participation. Psychiatry at stages of reforms: problems and prospects (Kazan, on September 23-26, 2015) [electronic resource]. N.G. Neznanov, ed. Saint-Petersburg: Alta Astra, 2015: 71 (in Russian).

16. Semke V.Ya., Pogosova I.A. Psihoterapiya komorbidnyh trevozhno-fobicheskih i affektivnyh rasstrojstv [Psychotherapy of comorbid anxiety-phobic and affective disorders]. Sibirskij vestnik psihiatrii $i$ narkologii - Siberian Herald of Psychiatry and Addiction Psychiatry. 2010; 5 (62): 50-57 (in Russian).

17. Tukaev R.D., Kuznetsov V.E. Kognitivnoorientirovannaya psihoterapiya pri trevozhnyh rasstrojstvah: ocenka v kontroliruemom issledovanii [Cognitive-oriented psychotherapy for anxiety disorders: an assessment in a controlled study]. Social'naya i klinicheskaya psihiatriya - Social and Clinical Psychiatry. 2015; 15 (2): 55-64 (in Russian).

18. Allen L.B., White K.S., Barlow D.H., Shear M.K., Gorman J.M., Woods S.W. Cognitive-Behavior Therapy (CBT) for panic disorder: relationship of anxiety and depression comorbidity with treatment outcome. J Psychopathol Behav Assess. 2010; 32 (2): 185-192. doi 10.1007/s10862-009-9151-3

19. Boswell J.F., Gallagher M.W., Sauer-Zavala S.E. et al. Patient characteristics and variability in adherence and competence in cognitive-behavioral therapy for panic disorder. Journal of Consulting and Clinical Psychology. 2013; 81 (3): 443-454 doi:10.1037/a0031437

20. Brown G.W., Goldberg D., Kendler K.S., Sirovatka P.J. et al. (eds.) Psychosocial origins of depressive and anxiety disorders. Diagnostic issues in depression and generalized anxiety disorder. Arlington, Virginia, 2010: 303-332.

Received October 15.2018 Accepted February 18.2019 
Pogosova Inna A., PhD, Associate Professor of psychiatry and psychosomatic medicine, Kursk State Medical University, Kursk, Russian Federation.

Golozubova Kristina N., medical psychologist, Pristenskaya Central District Hospital of the Health Committee of the Kursk Region, s. Pristen', Kursk Region, Russian Federation.

$\triangle$ Pogosova Inna A., inchikp@yandex.ru 